The impact of teachers' in-service workshops on grammar achievement: The case of Iranian intermediate EFL learners

Biria, Reza

Islamic Azad University, Isfahan (Khorasgan) Branch, Iran (Biria_reza@yahoo.com)

Salamat, Zeynab

Islamic Azad University, Isfahan (Khorasgan) Branch, Iran (Zeynab_Salamat@yahoo.com)

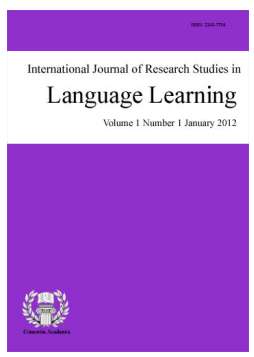

ISSN: $2243-7754$ Online ISSN: 2243-7762

OPEN ACCESS

\title{
Abstract
}

The present study aimed at quantitatively investigating the effectiveness of in-service workshops for teachers on Iranian intermediate EFL learners' L2 grammar achievement in a private language institute. To do so, Oxford Placement Test (OPT) was administered to homogenize the participants in terms of their level of proficiency. To collect the data, 40 intermediate learners took part in the study. Then, the participants were divided into one experimental group (i.e. receiving grammar practice by an in-service-trained teacher) and one control group (i.e. receiving no treatment and grammar practice by a non-in-service-trained teacher). The participants in the experimental and the control groups took the pre-test. After that, the experimental group was exposed to five treatment sessions of 'focus on form' approach of grammar instruction during five weeks, while the learners in the control group were given traditional grammar instruction. Then, the post-test was administered to both groups of the participants. It was concluded that the experimental group performed significantly better than the control group in the post-test measures of grammar tests highlighting the need for holding in-service workshops for teachers, particularly novice ones, and arm them to with the most recent knowledge of teaching language skills and sub-skills for the purpose of better teaching.

Keywords: in-service workshops; teacher education; grammar achievement; focus on form; teachers' awareness 


\section{The impact of teachers' in-service workshops on grammar achievement: The case of Iranian intermediate EFL learners}

\section{Introduction}

It is believed that the majority of teacher in-service workshops did not adequately prepare pre-service or in-service teachers to successfully meet the needs of learners. Szpara and Ahmad (2007) argue that the professional development that is usually offered in educational settings does not have a well-defined component devoted to the learners. What's worse, the planning and delivering of professional development seems to be fragmented by the existing departments.

Eun (2006) adds this point that educators and researchers generally believe and promote the concept that one of the best ways to improve the teaching and learning process is by providing teachers with quality professional development practices. The need for continuous improvement of professional skills and knowledge does not indicate that the workshops provided at the pre-service or in-service level was inadequate, rather it simply reveals that not everything language teachers need to know can be provided at the pre-service or in-service level, along with the fact that the knowledge base of language teaching is constantly changing (Guerra, 2008; Richards \& Farrell, 2005).

As Fielstein and Phelps (2001) state:

To grow as professionals, teachers must seek ways to overcome the isolation that has pervaded schools and classrooms... Within a school, students are not the only learners. It is important that teachers also view themselves as learners. Professional development should be an ongoing, personal responsibility rather than merely the school's agenda through its staff development program (pp. 322-323).

The language teacher education, which is in favor of holding workshops, should focus on who will be taught, what will be taught, how it will be taught, and how what is learned will be evaluated (Graves, 2009). The knowledge base of language teacher education should pay a careful attention to the teachers who practice it, the contexts in which it is carried out, and the pedagogy by which it is carried out (Johnson, 2006; Yates \& Muchisky, 2003). Generally, English language teachers must be equipped with not only pedagogical knowledge and teaching skills, but also knowledge about language (Ardila-Rey, 2008).

As workshops are held to prepare the teachers to have their best performance in the classroom practically in order to effectively teach the language skills and sub-skills and since grammar instruction, with the new focus on form approach, has been a concern for language teachers and educators, the present study seems to be innovative in that no studies, up to now, looked into the effectiveness of in-service workshops on the teachers' awareness of teaching grammar through focus on form approach and the learners' improvement of second language grammar. The study will be of great significance for teaching grammar since it highlights the need for professional development courses to be held for teacher to make their knowledge of teaching, particularly teaching grammar, more up- to-date, leading to their successful performance in the classroom and the learners' satisfaction as well.

\subsection{Research question}

The study seeks to answer whether in-service workshops for teachers have any impact on Iranian intermediate EFL learners' L2 grammar achievement? 


\section{Methodology}

\subsection{Participants}

For the purpose of data collection, there were 100 EFL learners who are studying in a private language institute in Isfahan, Iran. As to the homogeneity of the participants, they took Oxford Placement Test (OPT) for the purpose of unifying their levels to meet the requirements of the study. Therefore, 40 students were considered as intermediate learners after taking the placement test with the criteria of at least 1 standard deviation below to 1 standard deviation over the mean. It is noteworthy that they consisted of both male $(n=23)$ and female $(n=17)$ students with the age range of 14 to 20 years old. Two teachers (an in-service-trained teacher and a non-in-service-trained teacher) were selected via an interview. The participants were divided into one experimental group (i.e. receiving the treatment of grammar practice through 'focus on form' approach by an in-service-trained teacher) and one control group (i.e. receiving no treatment and being traditionally taught by a non-in-service-trained teacher). The experimental group included 20 participants and the control one consisted of 20 students as well. Regarding the learners' experience of learning English, the participants have been studying English for one year.

As to the data collection procedure, all the participants were invited to take part in the study in that some of them did not prefer to take part in the study and have been removed. Moreover, ethical issues regarding their anonymity and confidentiality have also been considered in order to allow the students to comfortably fill in the pre- and post-tests.

\subsection{Instrumentations}

The following instruments and materials were applied in the present study:

Oxford placement test (OPT) - Oxford Placement Test (OPT) was administered at the beginning of the study to select homogenous samples in terms of their proficiency levels. It is noteworthy that the participants of the study were of intermediate level and OPT was applied to select the students who are all intermediate learners. As to the purpose of the present study, OPT (version 1) was administered including 60 multiple choice items on vocabulary and grammar. The rationale behind the application of the OPT was firstly the fact that compared to the other tests, the participants of the study were believed to be more familiar with the structure of this test; therefore, they were expected to take the test better. Secondly, this test, as previously mentioned above, can assist the researcher to go for homogenous participants of the study.

English grammar diagnostic test (pre-test) - The English grammar diagnostic test, which was served as the pre-test of the study, was used to test the participants' initial knowledge of grammar and look into the probable problems they might face in dealing with understanding the grammatical forms. The pre-test included 25 multiple choice questions of grammar provided based on the learners' level and 'Grammar in Use' book (2009) (intermediate level). Total score was estimated at 25. The questions of the pre-test involved various types of grammatical forms including simple present, simple past, and present perfect tenses to be aware of the participants' initial understanding of 12 grammar knowledge. In fact, the aim of the pre-test was to give the researcher enough clues in terms of what to teach, how to teach, and what materials to be adopted to arm the learners with new teaching methodologies in grammar to get mastery linguistic entities and be able to overcome their grammar problems as well.

English grammar achievement test (post-test) - Similar to the pre-test, the English grammar achievement test, which was served as the post-test of the study, was applied to check the participants' 12 grammar knowledge and look into their probable progress as a result of receiving the treatment on grammar practice through 'focus on form' approach by an in-service-trained teacher. The same as the pre-test, the post-test contained 25 multiple choice questions of grammar provided based on the learners' level and 'Grammar in Use' book (2009) 
(intermediate level). Total score was estimated at 25. The questions of the pre-test involved various types of grammatical forms including simple present, simple past, and present perfect tenses to investigate the effectiveness of the treatment on the participants' final understanding of grammar and how they could improve their 12 grammar achievement. In fact, the aim of the post-test was to give the researcher enough clues in terms of the efficiency of teaching grammar by an in-service-trained teacher focusing on form-focused grammar instruction to get mastery over grammar.

\subsection{Procedures}

As previously mentioned in the introductory section of this chapter, the present study aimed to quantitatively collect the desirable data. To do so, the researcher made the required cooperation with the supervisor as well as the manger of the institute. The students were also informed in terms of anonymity and confidentiality to meet the requirements of ethical issues in research. Initially, Oxford Placement Test (OPT) was administered to distinguish the level of the students and homogenize the learners according to the purpose of study aiming to select intermediate learners. After the administration of the OPT among 100 students, 40 intermediate students with the criteria of at least 1 standard deviation below to 1 standard deviation over the mean were selected as the participants of the study. Then, they were divided into one experimental group (i.e. receiving the treatment of grammar practice through 'focus on form approach' by an in-service-trained teacher) and one control group (i.e. receiving no treatment and being traditionally taught by a non-in-service-trained teacher).

The experimental group included 20 participants and the control one consisted of 20 students as well. Both the experimental and the control groups took the pre-test of the study to measure their initial knowledge of grammar for the purpose identifying the probable weaknesses they might face in understanding grammatical forms. After the pre-test, the experimental group underwent five treatment sessions during five weeks. Each week included one 60-minute session of form-focused grammar instruction to make the learners motivated and allow them to experience an interactive learning environment by the use of language tasks. In each session, there were some tasks provided by the researcher and was shown on the screen while the participants were asked to do the related tasks of grammar without knowing what grammar tenses they were taught. As to the tasks, there were short texts provided for the learners with some comprehension questions focusing on simple present, simple past, and present perfect tenses. The learners were asked to read and answer the questions orally in the classroom with their peers and, whenever needed, teacher provided the support for the learners. In some sessions, to add variety to the classroom, the learners were shown some movies and they were asked to watch the movie carefully and be able to answer the questions according for the purpose of acquiring the above-mentioned grammatical forms. Some related pictures were also provided to activate the learners' background knowledge regarding the title of the movie and its events.

However, the control group did not receive such instruction, and they were traditionally taught by introducing them the exact grammatical forms and they were asked to do the grammar exercises with their peers and receiving the teacher's help where necessary. It seems that the class of this type might be boring for the learners since there might be no variety and real-life discussion in traditional instruction. After the treatment sessions, the participants in the experimental and control group took the post-test to check the participants' 12 grammar achievement and look into their probable progress as a result of receiving the treatment on grammar practice through 'focus on form' approach by an in-service-trained teacher. The experimental and control groups' scores were compared to find out the possible difference in grammar learning for the purpose of investigating the effectiveness of treatment sessions on the learners' 12 grammar achievement.

\subsection{Data analysis}

The present study applied quantitative methodology to collect and analyze the data. As to the data analysis, quantitative measures included both descriptive and inferential statistics to measure the impact of form-focused instruction vs. traditional instruction of teaching grammar on Iranian intermediate EFL learner L2 grammar 
achievement in a private language institute. To do so, the learners' pre- and post-tests results of the experimental and the control groups were quantitatively analyzed through SPSS software (version 20). The descriptive statistics shows the development of the mean scores on the two occasions of the English grammar diagnostic and achievement tests (i.e. pre- and post-tests). Additionally, inferential statistics involves an Independent Sample T-test in order to analyze the post-test scores of the study to look into the effectiveness of the treatment sessions on the learners' performance in grammar for the purpose of finding out the difference between the two occasions of each group of the study.

\section{Results}

The present research looked into the effectiveness of in-service workshops for the teachers on the learners' improvement of grammar. To do so, 40 participants were randomly selected and divided into experimental group (20 participants) and the control one (20 participants). In the beginning, they took the pre-test and their scores were found to be similar together. Then, the experimental group underwent the treatment including the application of focus on form approach in teaching grammar by an in-service-trained teacher, while the control group received traditional grammar instruction by a non-in-service-trained teacher. After the treatment, they took the post-test to check their grammar achievement and see whether the treatment sessions have had any effect on their grammar learning. In the following, the learners' mean scores of the pre- and post-test are presented to descriptively go for the data analysis. Then, inferential statistics are provided to figure out the effectiveness of treatment.

Information regarding the descriptive statistics of the study variables is shown in Table 1 . The range of scores is form 0 (minimum) to 50 (maximum). The Table shows the number of participants in both groups (i.e. experimental and control), the least and the most scores gained by the learners, mean score, standard deviation, and variance in the pre- and post-test.

\section{Table 1}

Descriptive Statistics of the Study Variable for the Pre- and Post-Test

\begin{tabular}{lcccccc}
\hline & $\mathrm{N}$ & Minimum & Maximum & Mean & SD & Variance \\
\hline Experimental Group. Pre & 20 & 17 & 33 & 23.76 & 5.60 & 31.42 \\
Control group. Pre & 20 & 15 & 35 & 23.60 & 6.31 & 39.90 \\
Experimental Group. Post & 20 & 29 & 41 & 34.90 & 3.78 & 14.30 \\
Control group. Post & 20 & 23 & 38 & 30.96 & 5.05 & 25.55 \\
Valid N (list wise) & 20 & & & & & \\
\hline
\end{tabular}

As the Table indicates, there was an increase in the mean scores of the learners in the experimental group from the pre-test (23.76) to the post-test (34.90), highlighting the effectiveness of the treatment sessions in terms of benefitting from form-focused instruction by an in-service-trained teacher in improving the learners' grammar learning ability. Although the learners in the control group improved their grammar achievement, the mean difference for the control group (7.36) is, to a large extent, smaller than the mean difference of the experimental group (11.4), which shows that receiving grammar instruction through meaningful interaction by an expert teacher could pave the way for the learners to gain improvement in their grammar achievement. In the following, inferential analysis of the data is provided.

In order to address the research question of the study regarding the effect of in-service workshops for teachers on Iranian intermediate EFL learners' grammar achievement, data analysis can be accounted for and the distribution of data should be checked. To check the normality assumptions, Kolmogorov-Smirnov test was applied to see whether parametric test can be used to analyze the data. If the normality level is less than 0.05 , the distribution is normal while more than 0.05 shows that the data are not normally distributed. The result of normality distribution is shown in Table 2. 
Biria, R., \& Salamat, Z.

Table 2

Kolmogorov-Smirnov Test for the Experimental and Control Group

\begin{tabular}{|c|c|c|c|c|c|}
\hline & & $\begin{array}{c}\text { Exp. Group. } \\
\text { Pre-test }\end{array}$ & $\begin{array}{c}\text { Control Group. } \\
\text { Pre-test }\end{array}$ & $\begin{array}{l}\text { Exp. Group } \\
\text { Post-test }\end{array}$ & $\begin{array}{c}\text { Control Group } \\
\text { Post-test }\end{array}$ \\
\hline$\overline{\mathrm{N}}$ & & 20 & 20 & 20 & 20 \\
\hline \multirow[t]{2}{*}{ Normal Parameters ${ }^{a, b}$} & Mean & 23.76 & 23.60 & 34.90 & 30.96 \\
\hline & SD & 5.60 & 6.31 & 3.78 & 5.05 \\
\hline \multirow[t]{3}{*}{ Most Extreme Differences } & Absolute & .23 & .14 & .16 & .19 \\
\hline & Positive & .23 & .14 & .16 & .15 \\
\hline & Negative & -.13 & -.14 & -.11 & -.19 \\
\hline Kolmogorov-Smirnov Z & & 1.29 & .79 & .88 & 1.03 \\
\hline Asymp. Sig. (2-tailed) & & .071 & .54 & .42 & .23 \\
\hline
\end{tabular}

Note. a. Test distribution is Normal. b. Calculated from data.

As the Table demonstrates, the normality level is more than 0.05 indicating that the data are normally distributed, therefore, justifying the application of parametric test. In order to compare the mean scores of the learners in the experimental and control group on the two occasions of pre- and post-test, independent sample t-test can be used to probe the effectiveness of in-service workshops for teachers on the learners' grammar achievement. Before taking the t-test results into account, it is of value to consider the experimental and control groups' mean scores in the pre-test. Table 3 shows the descriptive statistics for the learners' performance on the pre-and post-test.

\section{Table 3}

Descriptive Statistics of the Groups for the Pre-and Post-Test

\begin{tabular}{llllcc}
\hline & \multicolumn{1}{c}{ Group } & N & Mean & SD & Std. Error Mean \\
\hline Pretest & Experimental Group & 20 & 23.76 & 5.60 & 1.02 \\
& Control Group & 20 & 23.60 & 6.31 & 1.15 \\
Posttest & & & & \\
& & 20 & 34.90 & 3.78 & .69 \\
& Experimental Group & 20 & 30.96 & 5.05 & .92 \\
\hline
\end{tabular}

As to the Table, no special improvements can be seen in their mean scores on the pre-test. However, the post-test shows that the mean scores of the learners in the experimental group were more than the control group, which shows that the learners in the experimental group outperformed the control group. In order to inferentially analyze the post-test scores, independent sample t-test was applied to figure out the effectiveness of the treatment sessions on the learners' grammar achievement. Table 4 demonstrates the results of the learners' performance.

Table 4

Independent Sample T-Test for the Experimental and Control Groups

\begin{tabular}{|c|c|c|c|c|c|c|c|}
\hline \multirow{4}{*}{$\begin{array}{l}\text { Equal variances assumed } \\
\text { Equal variances not assumed }\end{array}$} & \multicolumn{2}{|c|}{ Levene's Test } & \multirow[b]{2}{*}{$\mathrm{t}$} & \multicolumn{3}{|c|}{ t-test for Equality of means } & \multirow[b]{2}{*}{ Std. Error } \\
\hline & $\mathrm{F}$ & Sig. & & df & Sig. (2-tailed) & $\begin{array}{c}\text { Mean } \\
\text { Difference }\end{array}$ & \\
\hline & 5.75 & .020 & 3.41 & 58 & .001 & 3.93 & 1.15 \\
\hline & & & 3.41 & 53.71 & .001 & 3.93 & 1.15 \\
\hline
\end{tabular}

Table 4 indicates that the normality level is 0.20 which is less than 0.05 , showing that the inequality of variances is verified. The sig vale $(0.01)$ is less than 0.05 , which highlights the effectiveness of the application of form-focused instruction by an in-service-trained teacher on the learners' grammar achievement. In other words, the learners in the experimental group positively responded to focus on form approach as a tool in teaching grammar and outperformed the control group.

In sum, the descriptive and inferential analysis showed that the learners in the experimental group could do better than the learners in the control group in grammar achievement. In fact, the control group, which received the traditional grammar instruction without an in-service-trained teacher, had weak performance in their post-test 

scores in relation to the experimental group.

\section{Discussion and conclusion}

The present study was an attempt to quantitatively look into the impact of teaching grammar through 'focus on form' approach by an in-service-trained teacher on the Iranian intermediate EFL learners' 12 grammar achievement. Based on the quantitative results of the pre- and post- test scores of the learners in the experimental and control group, it was revealed that the experimental group significantly outperformed the control group after the treatment (i.e. grammar practice through 'focus on form approach' by an in-service-trained teacher), indicating that the instruction was quite successful in improving the students' ability to produce the focused grammatical forms (simple present, simple past, and present perfect tenses). Although it was concluded that the participants of both groups performed better on the post-test measures of 12 grammar achievement, the experimental group, which was taught through form-focused instruction by an in-service-trained teacher, outperformed the control group, which underwent the traditional method of grammar instruction. Hence, the study, to a large extent, proved that the application of 'focus on form' approach in teaching language skills in general, and grammar in particular, which was the focus of the current research, can be productive to improve the learners' grammar learning by involving them in a rather different and interactive environment by the use of target tasks.

It should be noted that, up to the present, there seems to be no study done to highlight the impact of in-service workshops on the teachers' awareness of teaching grammar through focus on form approach and the learners' improvement of second language grammar. Hence, findings of the study are in line with the research done by Long (1983) or Doughty and Williams (1998) who highlighted the role of form-focused instruction in teaching grammar and its high effectiveness in paving the way for the learners to experience an interactive environment by participating in the classroom discussion made by the use of language tasks for the purpose of fostering communication and encouraging peer or teacher-learner interaction.

Another point to be taken into account is the notion of regulation, which is of importance in sociocultural theory in that learner, can regulate their learning behavior. In fact, as to the findings of the study, the learners' pre-test scores showed that learners need special support by their teachers in learning grammar, which is, according to Vygotsky (1978), called as other-regulation that the teacher acts as a mediator give enough feedback for the learners to become autonomous learners during the process of time in which they move toward self-regulation as the learners' post-test scores highlighted that the learners could acquire the grammatical forms more independently although the teacher provided the feedback where necessary, however; his support was less than the beginning of the term and before the treatment sessions.

\subsection{Implication}

The findings of the study clearly acknowledged that grammar instruction by an in-service-trained teacher through 'focus on form' approach led to the improvement in the learners' 12 grammar achievement. It was found that sociocultural theory, which is concerned with creating interaction in any educational setting through the application of language tasks, can be utilized to justify the use of 'focus on form' approach and benefiting from in-service-trained-teacher (as the mediator) to provide support for the learners in the classroom since it paved the way for the learners to acquire the grammatical forms with the help of the teacher's feedback while assisting them to take part in classroom talks with their peers as well as the teacher and implicitly learn the target grammatical form as a result of the so-called interaction. The present research has been quantitatively done to measure the learners' pre- and post-test scores of grammar diagnostic achievement tests as a result of receiving form-focused instruction, thus, paving the way for future qualitative research in order to interpretively look into the effectives of 'focus on form' approach in teaching grammar and other sub-skills.

The findings of the study suggest some productive and practical implications in terms of the educational 
setting adopted in teaching and learning grammatical form through 'focus on form' approach in a foreign language context such as Iran. The main practical implications include:

1. Learners are the first beneficiary of the form-focused instruction by an in-service-trained teacher since they can start communication in the target language while focusing on the form without being directly given the grammar instruction. In fact, teachers' mastery over form-focused instruction may result in the learners' interaction caused by the adoption of the so-called approach to teach grammar within the context in which they participate in classroom talk while the teacher attracts the learners' attention to the form implicitly.

2. Teachers can also benefit from 'focus on form' approach to teach grammar and separate from traditional method of grammar instruction. Novice teachers particularly can promote their knowledge of grammar instruction with the purpose of being familiar with newly adopted methodologies (such as focus on form approach) and improve their teaching qualities of grammar instruction for the purpose of creating an interactive learning environment for the learners.

3. Teacher educators who are concerned with effective and better teaching can hold education programs to raise the teachers' awareness of newly introduced teaching methodologies of grammar instruction in order to enhance their knowledge of teaching grammar. The findings of the study can give opportunities to teacher educators to make their best attempts in order to hold in-service workshops in all aspect of English language teaching and employ the best of educators who are well-informed of the most modern and productive methods of teaching language skills to raise the teachers' awareness, which will result in the learners' better learning situation and satisfaction as well.

4. Finally, regarding the significance of teaching grammar through 'focus on form' approach, material developers are also able to make the effective use of this approach and design the required materials while focusing on the so-called approach in order to arm the learners with an interactive environment caused by the teachers' application of pedagogic tasks to foster communication within the context of meaningful interaction for the purpose of grammar learning.

\subsection{Suggestion for further research}

The present study benefitted from quantitative methodology to investigate the effectiveness of teaching grammar through 'focus on form' approach by an in-job-trained teacher on the Iranian intermediate EFL learners' 12 grammar knowledge. Findings showed that the experimental group significantly outperformed the control group after the treatment (i.e. grammar practice through 'focus on form approach' by an in-job-trained teacher), indicating that the instruction was quite successful in improving the students' ability to produce the focused grammatical forms (simple present, simple past, and present perfect tenses). However, quantitative results seem not to adequately justify the effectiveness of form-focused instruction by an in-job-trained teacher on the learners' grammar learning. In fact, qualitative research, which is concerned with interpretive analysis of data, can be taken into account to consider the learners and teachers' talk in the classroom through conversation analytic perspective to analyze how interaction and the flow of communication takes place in the classroom and provides better support for quantitative data. Future research can maneuver on qualitative methodology of form-focused instruction to go for the learners' performance within the classroom interaction by analyzing the peer and learner-teacher interactions.

\section{References}

Ardila-Rey, A. (2008). Language, culture, policy, and standards in teacher preparation: Lessons from research and model practices addressing the needs of CLD children and their teachers. In M. E. Brisk (Ed.), Language, culture, and community in teacher education (pp. 331-352). New York, NY: Taylor \& Francis Group.

Doughty, C, \& Williams, J. (Eds.). (1998). Focus on form in classroom language acquisition. Cambridge: 


\section{Cambridge University Press.}

Eun, B. (2006). The impact of English as second language professional development program: A social cognitive approach (Unpublished doctoral dissertation). University of North Carolina, North Carolina.

Fielstein, L., \& Phelps, P. (2001). Introduction to teaching. Belmont, CA: Thomson Learning.

Graves, K. (2009). The curriculum of second language teacher education. In A. Burns \& J. C. Richards (Eds.), The Cambridge guide to second language teacher education (pp. 115-124). New York, NY: Cambridge University Press.

Guerra, A. (2008). The impact of professional staff development on instruction for English language learners (Unpublished doctoral dissertation). Aurora University, Illinois.

Johnson, K. E. (2006). The sociocultural turn and its challenges for second language teacher education. TESOL Quarterly, 40(1), 235-256. https://doi.org/10.2307/40264518

Long, M. (1983). Native speaker/non-native speaker conversation and the negotiation of comprehensible input. Applied Linguistics, 4, 126-141. https://doi.org/10.1093/applin/4.2.126

Richards, J., \& Farrell, T. (2005). Professional development for language teachers. New York, NY: Cambridge University Press. https://doi.org/10.1017/CBO9780511667237

Szpara, M., \& Ahmad, I. (2007). Supporting English-language learners in social studies class: Results from a study of high school teachers. Social Studies, 98(5), 189-195. https://doi.org/10.3200/TSSS.98.5.189-196

Vygotsky, L.S. (1978). Mind in society. The development of higher psychological processes. Cambridge, Mass: Harvard University Press.

Yates, R., \& Muchisky, D. (2003). On reconceptualizing teacher education. TESOL Quarterly, 37(1), 135-146. https://doi.org/10.2307/3588468 
Biria, R., \& Salamat, Z. 